\title{
Effect of combined music and touch intervention on pain response and $\beta$-endorphin and cortisol concentrations in late preterm infants
}

\author{
Jie Qiu ${ }^{1 \dagger}$, Yun-fei Jiang ${ }^{2+}$, Fang Li', Qian-hong Tong ${ }^{1}$, Hui Rong ${ }^{1}$ and Rui Cheng ${ }^{1 *}$
}

\begin{abstract}
Background: Preterm neonates undergo many painful procedures as part of their standard care in the neonatal intensive care unit. However, pain treatment is inadequate in many of these routine procedures. In the present study, we investigated the impact and mechanism of combined music and touch intervention (CMT) on the pain response in premature infants.

Methods: Sixty-two preterm neonates (gestational age of $<37$ weeks) were randomly assigned to either the experimental or control group. Infants in the experimental group underwent painful procedures with CMT, and those in the control group underwent painful procedures without CMT. Blood samples were collected from all infants at the beginning of hospitalization and 2 weeks later to assess the cortisol and $\beta$-endorphin concentrations. Differences in the levels of cortisol and $\beta$-endorphin between two groups were examined using analysis of covariance (ANCOVA).

Results: In total, 3707 painful procedures were performed on 62 neonates during their hospitalization. The average number of painful procedures in the control group $(n=35.5)$ was higher than that in the experimental group $(n=29.0)$ during hospitalization, although no significant difference was reached $(P>0.05)$. After 2 weeks, the Premature Infant Pain Profile scores were significantly higher in the control group than experimental group $(13.000 \pm 0.461$ vs $10.500 \pm 0.850$, respectively; $P<0.05)$. The cortisol concentration was not significantly different between the control and experimental groups either at the beginning of hospitalization (131.000 \pm 18.190 vs 237.200 \pm 43.860 , respectively; $P>0.05)$ or 2 weeks later $(162.400 \pm 23.580$ vs $184.600 \pm 21.170$, respectively; $P>0.05)$. However, the serum $\beta$-endorphin concentration was higher in the experimental group than in the control group both at the beginning of hospitalization ( $1.640 \pm 0.390$ vs $1.179 \pm 0.090$, respectively; $P<0.05)$ and 2 weeks later $(2.290 \pm 0.740$ vs $1.390 \pm 0.410$, respectively; $P<0.05)$.
\end{abstract}

Conclusions: CMT might decrease the pain response of preterm neonates by significantly improving the $\beta$-endorphin concentration, but not the blood cortisol concentration.

Trial registration: Current Controlled Trials ISRCTN14131492. Registered on 01 Aug 2016.

Keywords: Preterm infant, Pain, Cortisol, $\beta$-Endorphin, Music, Touch

\footnotetext{
* Correspondence: chengrui350@163.com

${ }^{\dagger}$ Equal contributors

'Department of Newborn Infants, Children's Hospital of Nanjing Medical

University, Nanjing 210008, China

Full list of author information is available at the end of the article
} 


\section{Background}

Preterm neonates undergo many painful procedures as part of their standard care in the neonatal intensive care unit (NICU) [1, 2]. Accumulating evidence shows that preterm infants are able to experience pain [3, 4] and are highly sensitive to pain because of their immature and vulnerable nervous systems [5]. Repetitive, prolonged, and poorly treated pain has many deleterious consequences. Short-term effects include excessive crying, choking, gagging, vomiting, and long-term effects include altered pain sensitivity as well as permanent neuroanatomical and behavioral abnormalities [6]. Therefore, there is an urgent need to establish safe and effective treatments for pain relief in infants.

However, pain treatment for routine procedures in the $\mathrm{NICU}$ is inadequate. In fact, many doctors are reluctant to use analgesic medications such as nonsteroidal antiinflammatories or acetaminophen in the NICU because the effectiveness of these medications has not been proven or because of potential adverse effects in the short term (e.g., opioid-induced ileus or apnea) or long term (e.g., ketamine-induced neuroapoptosis). Various nonpharmacological treatments, including non-nutritive sucking both with and without sucrose, swaddling or kangaroo care, music therapy, and multisensorial stimulation, reportedly exert a pain-modulating effect on preterm neonates because they activate the neonates' attention, distract them from the pain, and thus modify pain perception [7-14]. Music therapy may help to relieve procedural pain in both full-term and preterm infants because it can provide an auditory stimulus that modulates pain perception, obviating or decreasing the need for pharmacological agents $[10,12,13,15,16]$. Another nonpharmacological intervention, touching, also helps to reduce pain in preterm and term neonates. Prasopkittikun and Tilokskulchai [17] reported that touching, swaddling, maternal holding, and repositioning were effective nonpharmacological interventions that reduced pain using validated pain assessment measures in preterm and term infants. However, a combination of these nonpharmacological interventions may be more useful because their effectiveness may vary across infants. Furthermore, few data specifically address premature infants, who are exposed to the most procedural pain and are the most vulnerable to altered developmental trajectories in childhood. Especially in China, no study has addressed the effects of combined music and touch intervention (CMT) on the pain response in late preterm infants. Therefore, in the present study, we investigated the impact of CMT on the premature infant pain response. We also studied the levels of cortisol and $\beta$-endorphin after the intervention because these parameters may provide evidence of the effectiveness of CMT in alleviating pain in premature infants. Pain may activate the hypothalamic-pituitary-adrenal (HPA) axis, inducing an endocrine response in premature infants that increases cortisol levels [18]. Cortisol affects the metabolism, cardiovascular system, and central nervous system [19]. In various studies, cortisol has been used to assess the effects of nonpharmacological interventions against pain in newborn infants, including sucrose, the kangaroo position, and developmental care [20-22]. $\beta$ Endorphin is an endogenous opioid that is released in response to pain and increases the inhibition of pain at several sites within the $\beta$-endorphin inhibitory pathway. It is released when an organism is exposed to stress or painful stimuli. During acute stress and pain, the HPA system increases the blood $\beta$-endorphin concentration. This circulatory release of $\beta$-endorphin can be reduced by systemic analgesia [23-25]; thus, plasma $\beta$-endorphin concentrations have frequently been used to determine analgesic efficacy.

The purpose of this study was to examine whether CMT is an effective pain management method for premature infants during the painful procedures performed on a daily basis in the NICU. We compared the Premature Infant Pain Profile (PIPP) scores and cortisol and $\beta$ endorphin concentrations between infants who did and did not receive CMT. To the best of our knowledge, this is the first study to examine the relationship between CMT and the pain response in premature infants.

\section{Methods \\ Participants}

This randomized controlled trial was conducted in the NICU of Children's Hospital of Nanjing Medical University from June 2011 to March 2012. The inclusion criteria were as follows: (1) admission within $72 \mathrm{~h}$ after birth and (2) a gestational age of $<37$ weeks. The exclusion criteria were one or any combination of the following: (1) serious birth injuries, (2) serious malformations (especially in the oral cavity or external ear), (3) significant parenchymal brain injury (grade IV intraventricular hemorrhage or periventricular leukomalacia), (4) treatment with analgesics or sedatives within $72 \mathrm{~h}$ of the assessment, or (5) failed hearing screening.

\section{Procedures}

The research team comprised a neonatologist, three research nurses, a child health care expert, and three assistants with extensive research and clinical experience. A list of daily painful procedures was designed [26-28]; this list also included other procedures that the clinicians or nurses considered painful, such as tracheal aspiration, nasal aspiration, removal of intravenous lines, and removal of adhesives (Table 2). After consent was obtained from the infants' parents, the infants were randomly assigned to either the experimental or control 
group using a random numbers table. Infants in the control group underwent daily painful procedures without intervention. Infants in the experimental group underwent painful procedures with CMT. Only nurses on the research team administered the CMT to ensure consistency. A compact disc player (AZ-1103; Philips, Amsterdam, Netherlands) was used for the music intervention. Audio stimulation was provided by "Smart Baby Lullaby" compact discs. The music included lullabies and nursery rhymes, which are musically simple songs with a lower pitch and slower tempo. The most appropriate decibel level for the disc player was determined to be 55 to 65 decibels $(\mathrm{dB})$ using an A-weighted scale, measured using a TES-1351B Sound Level Meter (TES Electrical Electronic Corp., Taipei, Taiwan). This volume level was implemented to meet criteria consistent with current knowledge of infant auditory development in relationship to the ambient NICU sound environment. Music applications of 55 to $65 \mathrm{~dB}$ for short-timed interventions met the recommendations for infants and supported a variance of $10 \mathrm{~dB}$ between the ambient sound floor and sound interventions to ensure audibility [29]. Although environmental sound was not within the scope of this investigation, the staff members in our NICU were cognizant of the noise and ambient sounds. The disc player was placed approximately 15 to $20 \mathrm{~cm}$ above the infants' heads, which allowed for continuous play of the music from $5 \mathrm{~min}$ before the experimental procedure until $30 \mathrm{~min}$ after the procedure. The touch intervention protocol (Gentle Human Touch, GHT), started from the beginning of each procedure until $10 \mathrm{~min}$ after the procedure and was performed as previously described [30]. Briefly, the nurse gently placed her left hand on the infant's head with her fingertips resting immediately above the eyebrow line and her palm touching the infant's crown. Her right hand was placed with the right thumb on the infant's right shoulder (midline position) with the rest of her hand and fingers on the infant's arm, above the elbow. The video camera was positioned for a closeup of the face. The signals were fed directly to a VCR before, during, and after each painful procedure. These procedures were repeated for every painful procedure during the 2-week data collection period.

\section{PIPP}

The PIPP is a pain measure for premature infants and comprises seven indicators: two contextual (gestational age and behavioral state), two physiologic (heart rate and oxygen saturation), and three behavioral (brow bulge, eye squeeze, and nasolabial furrow). Each indicator is scored on a 4-point scale (0-3) for a maximum total score of 21 [31, 32]. The internal consistency and inter- and intra-rater reliability were summarized with good face validity and content validity in a review article on pain assessment in children [32]. Video sequences were assessed by three different nurses. The three nurses were supervised to ensure that they did not consult one another, and all were blinded to the intervention $v s$ control group.

\section{Cortisol and $\beta$-endorphin concentrations}

The $\beta$-endorphin concentration is known to exhibit a circadian rhythm that repeats once in a $24-h$ period. Therefore, a 2-ml blood sample was collected from each infant between 6 and 7 AM to minimize any circadian rhythm effects. The cortisol and $\beta$-endorphin concentrations were quantitatively assessed using a highly sensitive electrochemiluminescence immunoassay (Roche Diagnostics, Mannheim, Germany) and a modular analytics analyzer (Elecsys Modular Analytics E170; Roche Diagnostics, Tokyo, Japan).

\section{Statistical analysis}

Unless otherwise stated, numerical results are presented as the mean \pm standard error of the mean. Statistical analyses were performed using the SPSS 19.0 statistical package (IBM Corp., Armonk, NY, USA). Demographic data and pain experience were compared between the two groups using the unpaired $t$-test (normally distributed data), the Mann-Whitney $U$ test (non-normally distributed data), or Fisher's exact test (categorical data). Gestational ages were compared using one-way analysis of variance and the least significant difference test. Wilcoxon signed-rank tests were carried out to examine PIPP scores. ANCOVA was used to evaluate the difference in the levels of cortisol and $\beta$ endorphin between two groups. Statistical significance was defined as $P<0.05$.

\section{Results \\ Demographic variables}

During the study period (June 2011 to March 2012), 74 of 141 eligible infants were enrolled in this study (flow diagram, Fig. 1). We excluded seven neonates in the experimental group and five neonates in the control group who were discharged within 2 weeks. Thus, 62 neonates were finally included in the analysis. The primary purpose of the pilot study was to refine the study methodology and obtain adequate data with which to conduct an analysis for an expanded study. Based on the advice of a biostatistician, a sample size of 30 was determined to be adequate for this purpose. In addition, the severity of illness was assessed using the Score for Neonatal Acute Physiology II [33]. Table 1 shows the demographic characteristics of the neonates. There were no differences in the demographic characteristics between the experimental and control groups. 


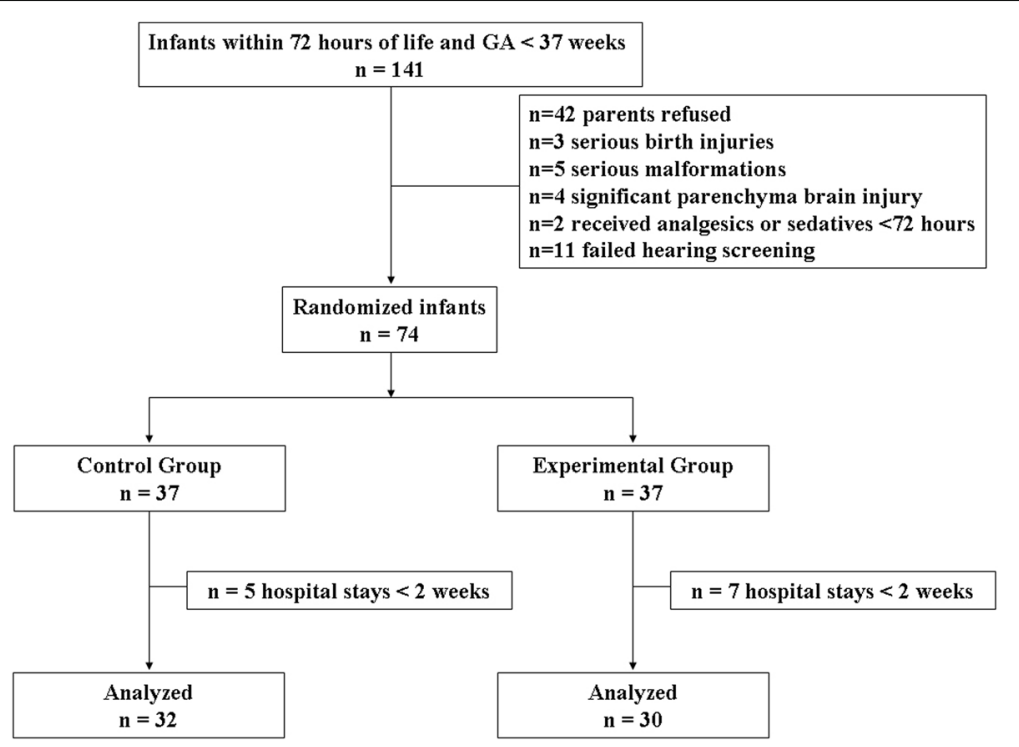

Fig. 1 Study profile and patient flow

\section{Numbers and types of pain experiences}

In total, 3707 painful procedures were performed on 62 neonates during their hospitalization. Among these procedures, 1913 were performed in the control group and 1794 were performed in the experimental group. The median number of painful procedures for each preterm neonate in the control group was 35.5 (range, 18-325). The median number in the experimental group was 29 (range, 14-316). The average number of painful procedures in the control group was higher than that in the experimental group during hospitalization, although no statistical difference was reached $(P>0.05)$. The types of painful procedures performed on the neonates are listed in Table 2.

\section{PIPP}

The mean PIPP scores were $11.17 \pm 0.91$ and $12.14 \pm$ 0.46 (control vs. experimental), respectively, at the beginning of the hospitalization. After 2 weeks, the PIPP score in the control group had significantly increased

Table 1 Clinical and demographic characteristics of neonates

\begin{tabular}{llll}
\hline & $\begin{array}{l}\text { Control group } \\
n=32\end{array}$ & $\begin{array}{l}\text { Experimental group } \\
n=30\end{array}$ & $P$ \\
\hline Gestational age (weeks) & $33.33 \pm 0.54$ & $34.30 \pm 0.67$ & 0.10 \\
Birth weight (kg) & $2.00 \pm 0.07$ & $1.93 \pm 0.13$ & 0.64 \\
Sex (male/female) & $15 / 17$ & $13 / 17$ & 0.80 \\
1-min APGAR & $8.67 \pm 0.24$ & $9.37 \pm 0.32$ & 0.96 \\
5-min APGAR & $9.40 \pm 0.22$ & $9.64 \pm 0.15$ & 0.47 \\
Severity (SNAP-II) & $8(0-57)$ & $8(0-33)$ & 0.69 \\
\hline
\end{tabular}

Data are presented as mean \pm SD or median (range)

APGAR indicates appearance, pulse, grimace, activity, respiration $(\mathrm{t}=2.573 ; \quad P<0.05)$ and that in the experimental group had significantly decreased $(t=2.216 ; P<0.05)$. There was no significant difference between the two groups at the beginning. Two weeks later, however, the experimental group had a significantly lower score than the control group $(10.50 \pm 0.85$ vs $13.00 \pm 0.46$, respectively; $P<0.05$ ) (Fig. 2 ).

\section{Cortisol concentration}

In the control group, the cortisol concentration significantly decreased after 2 weeks of hospitalization $(131.00 \pm 18.19$ vs $237.20 \pm 43.86$, respectively; $P<$ $0.05)$. Additionally, no significant changes occurred in the experimental group from the beginning of hospitalization to 2 weeks later $(184.60 \pm 21.17$ vs $162.40 \pm$ 23.58, respectively; $P>0.05$ ). No significant differences were noted between the two groups either at the beginning of hospitalization or 2 weeks later (Fig. 3).

\section{$\beta$-Endorphin}

The $\beta$-endorphin concentration increased significantly in the experimental group, but not in the control group, after 2 weeks $(P<0.05)$. Neonates in the experimental group had higher $\beta$-endorphin levels than those in the control group both at the beginning of hospitalization $(1.64 \pm 0.39$ vs $1.18 \pm 0.09$, respectively; $P<0.05)$ and 2 weeks later $(2.29 \pm 0.74$ vs $1.39 \pm 0.41$, respectively; $P<0.05)$ (Fig. 4).

\section{Discussion}

In this study, we randomly assigned 62 preterm neonates to either an experimental or control group to demonstrate whether CMT can relieve pain such patients in the 
Table 2 Types of painful procedures on neonates

\begin{tabular}{lll}
\hline Procedure Types & $\begin{array}{l}\text { Procedure no. (\%) } \\
\text { on control group }\end{array}$ & $\begin{array}{l}\text { Procedure no. (\%) on } \\
\text { experimanetal group }\end{array}$ \\
\hline Tracheal aspiration & $183(9.57)$ & $165(9.20)$ \\
Nasal aspiration & $283(14.79)$ & $241(13.43)$ \\
Intravenous cannulation & $256(13.38)$ & $231(12.88)$ \\
Removal of intravenous lines & $229(11.97)$ & $206(11.48)$ \\
Adhesive removal & $229(11.97)$ & $206(11.48)$ \\
Fingerstick & $89(4.65)$ & $95(5.30)$ \\
Heelstick & $69(3.61)$ & $85(4.74)$ \\
Femoral venous puncture & $108(5.65)$ & $107(5.96)$ \\
Arterial puncture & $53(2.77)$ & $49(2.73)$ \\
Laxative or enema & $48(2.51)$ & $43(2.40)$ \\
Gastric tube insertion & $34(1.78)$ & $30(1.67)$ \\
Tracheal intubation & $7(0.37)$ & $6(0.33)$ \\
Tracheal extubation & $7(0.37)$ & $6(0.33)$ \\
Chest physiotherapy & $285(14.90)$ & $295(16.44)$ \\
Lumbar puncture & $9(0.47)$ & $8(0.45)$ \\
Intradermal injection & $24(1.25)$ & $21(1.17)$ \\
Total & $1913(100.01)$ & $1794(99.99)$ \\
\hline & &
\end{tabular}

NICU. Infants in the experimental group underwent daily painful procedures with CMT, while those in the control group underwent daily painful procedures without interference. Details on the daily painful procedures, PIPP scores, and circulatory cortisol and $\beta$-endorphin concentrations were analyzed at the beginning of hospitalization and 2 weeks later.

The hospitalized preterm neonates in this study underwent an average of 29.0 to 35.5 painful procedures during 2 weeks of hospitalization. Among these procedures, those related to tracheal aspiration (e.g., tracheal aspiration, nasal aspiration, and chest physiotherapy) and

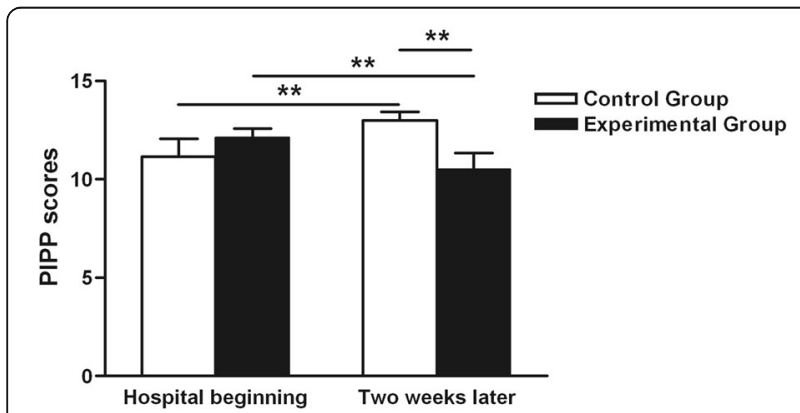

Fig. 2 Effects of CMT on PIPP. The mean PIPP scores were 11.17 \pm 0.91 and $12.14 \pm 0.46$ (control vs. experimental) at the beginning of the hospitalization, respectively. There was no significant difference between the two groups at the beginning of hospitalization (** $P>0.05)$. Two weeks later, the experimental group had significantly lower scores than the control group (10.50 \pm 0.85 vs $\left.13.00 \pm 0.46,{ }^{* *} P<0.05\right)$

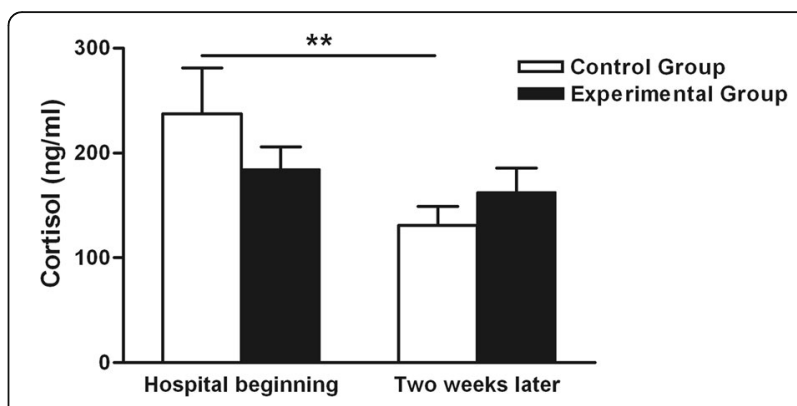

Fig. 3 Effects of CMT on cortisol concentration. In the control group, the cortisol concentration had significantly decreased after 2 weeks of hospitalization vs the beginning ( $131.00 \pm 18.19$ vs $237.20 \pm 43.86$, respectively; $\left.{ }^{* *} P<0.05\right)$, while there was no significant change in the experimental group after 2 weeks vs the beginning (162.40 \pm 23.58 vs $184.60 \pm 21.17$, respectively; $\left.{ }^{* *} P>0.05\right)$. No significant difference was noted between the two groups either at the beginning of hospitalization or 2 weeks later

intravenous cannulation (e.g., intravenous cannulation, removal of intravenous lines, and adhesive removal) are the most frequent types of painful procedures performed among preterm infants. This might be because preterm infants commonly have complications such as breathing difficulties and nutrient defects. These complications lead most preterm neonates to require ventilation, support, and prolonged infusion of parenteral nutrition. Thus, the numbers of related procedures are significantly increased.

The PIPP was chosen as the pain measurement tool for this study because it is a composite of seven multidimensional indicators of pain. These pain indicators include physiological, behavioral, and contextual measures that adjust for the influence of gestational age at the time of treatment and the infant's state of awareness [34-37]. As shown in Fig. 2, after 2 weeks, the PIPP score in the control group had significantly increased and that in the experimental group had significantly

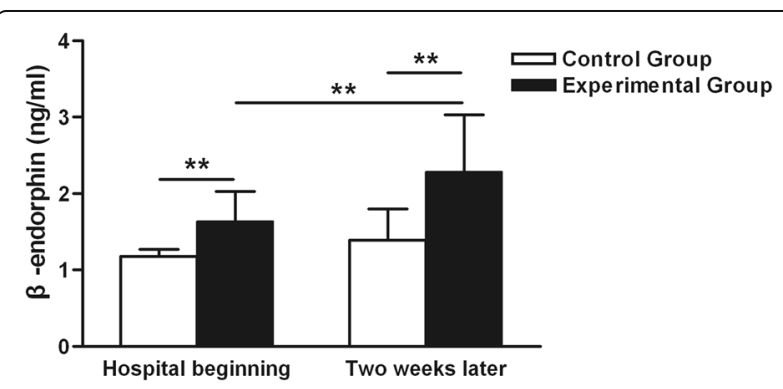

Fig. 4 Effects of CMT on $\beta$-endorphin concentration. Neonates in the experimental group had higher serum $\beta$-endorphin levels than those in the control group both at the beginning of hospitalization $\left(1.64 \pm 0.39\right.$ vs $1.18 \pm 0.09$, respectively; $\left.{ }^{* *} P<0.05\right)$ and 2 weeks later ( $2.29 \pm 0.74$ vs $1.39 \pm 0.41$, respectively; $\left.{ }^{*} P<0.05\right)$. The $\beta$-endorphin concentration increased significantly in the experimental group after 2 weeks, but not in the control group 
decreased; the PIPP score in the experimental group was significantly lower than that in the control group. Therefore, we presume that CMT can reduce the pain response in premature infants.

Cortisol, the steroid end product of the HPA axis, increases with painful procedures [38] and decreases with comforting procedures such as massage [39] and skin-to-skin care [40] in preterm infants. Thus, we supposed that the cortisol concentration would not differ between the two groups at the beginning of hospitalization and would significantly increase in the control group but not in the experimental group after 2 weeks of hospitalization. However, although there was no significant difference in the cortisol concentration between the two groups in this study, the cortisol concentration in the experimental group was slightly lower than that in the control group after a single blood collection at the beginning of hospitalization. After 2 weeks, the cortisol concentration had decreased in both groups, especially in the control group, in which the cortisol concentration had significantly decreased against the beginning of hospitalization. Two meaningful hypotheses can be offered to explain this phenomenon. First, at the beginning of hospitalization, the cortisol level in the control group increased because of a single painful procedure while that in the experimental group decreased because of a single CMT procedure. Measurement of the salivary cortisol concentration may be more accurate because there is no painful procedure at first. This would allow comparison of the baseline concentration and subsequent concentrations after single or repeated pain exposures. Second, after 2 weeks of hospitalization, the lower cortisol concentration may have occurred because repeated exposure to procedural pain was associated with downregulation of the HPA axis, such that the cortisol responses were dampened while the infants were still in the hospital [41]. Overall, the HPA axis responsiveness, cortisol regulation, and normal cortisol concentrations in preterm infants are very complex, and continued research is needed.

In this study, at the beginning of hospitalization, we found that the $\beta$-endorphin concentration significantly increased in the preterm infants of the experimental group after a single CMT; this prompted the $\beta$ endorphin concentration to change immediately after the intervention. However, no significant differences in the PIPP scores were detected at the beginning. After 2 weeks, the $\beta$-endorphin concentration in the experimental group had significantly increased while that in the experimental group had significantly decreased. These data suggest that in preterm infants, although the $\beta$-endorphin concentration increased, the increase was not adequate to reduce the pain response after a single intervention; repeating CMT might decrease the pain response by improving the $\beta$-endorphin concentration.

This study has shown that CMT is effective in comforting late preterm infants when they undergo painful procedures. As advocates for premature infants, neonatal nurses must continually explore treatment modalities to provide these infants with quality care and hope for a bright future. CMT plays a potential role in this field. A limitation of this study is that it was a pilot study with a small sample size; it would be advantageous to enlarge the sample size. Furthermore, it was a singlecenter case series that may not represent the situation in China as a whole. Thus, future studies involving other NICUs are needed to map the epidemiology of neonatal pain in China.

\section{Conclusions}

CMT might decrease the pain response of preterm neonates by improving the $\beta$-endorphin concentration, but not the blood cortisol concentration.

\section{Abbreviations \\ CMT: Combined music and touch intervention; HPA axis: Hypothalamic- pituitary-adrenal axis; NICU: Neonatal intensive care unit; PIPP: Premature Infant Pain Profile}

\section{Acknowledgements}

Not applicable.

\section{Funding}

This project was supported by grants from Nanjing Health bureau (YKK12108).

Availability of data and material

All the data and materials used are included in the manuscript. The datasets used and/or analysed during the current study available from the corresponding author on reasonable request.

\section{Authors' contributions}

JQ was an assistant of the research team, measured the cortisol concentration, and performed the statistical analysis. YFJ was an assistant of the research team and measured the $\beta$-endorphin concentration. $\mathrm{FL}, \mathrm{QHT}$, and $\mathrm{HR}$ were research nurses of the research team. RC was a neonatologist of the research team and participated in the study's design and coordination. All authors read and approved the final manuscript.

\section{Competing interests}

The authors declare that they have no competing interests.

Consent for publication

Not applicable.

Ethics approval and consent to participate

The study was approved by the Children's Hospital of Nanjing Medical University's Ethics Research Committee, and written consent was obtained from the parents of all participating infants.

\section{Author details}

${ }^{1}$ Department of Newborn Infants, Children's Hospital of Nanjing Medical University, Nanjing 210008, China. Department of Pediatrics, Yixing People's Hospital Affiliated to Jiangsu University, Yixing 214200, China.

Received: 19 July 2015 Accepted: 7 December 2016

Published online: 26 January 2017 


\section{References}

1. Johnston CC, Collinge JM, Henderson SJ, Anand KJ. A cross-sectional survey of pain and pharmacological analgesia in Canadian neonatal intensive care units. Clin J Pain. 1997:13:308-12.

2. Simons SH, van Dijk M, Anand KS, Roofthooft D, van Lingen RA, Tibboel D. Do we still hurt newborn babies? A prospective study of procedural pain and analgesia in neonates. Arch Pediatr Adolesc Med. 2003;157:1058-64.

3. Giannakoulopoulos X, Teixeira J, Fisk N, Glover V. Human fetal and maternal noradrenaline responses to invasive procedures. Pediatr Res. 1999;45:494-9.

4. Anand KJ, Carr DB. The neuroanatomy, neurophysiology, and neurochemistry of pain, stress, and analgesia in newborns and children. Pediatr Clin North Am. 1989;36:795-822.

5. Andrews K, Fitzgerald M. The cutaneous withdrawal reflex in human neonates: sensitization, receptive fields, and the effects of contralateral stimulation. Pain. 1994:56:95-101.

6. Batton DG, Barrington KJ, Wallman C. Prevention and management of pain in the neonate: an update. Pediatrics. 2006;118:2231-41.

7. Stevens B, Gibbins S, Franck LS. Treatment of pain in the neonatal intensive care unit. Pediatr Clin North Am. 2000;47:633-50.

8. Cignacco E, Hamers JP, Stoffel L, van Lingen RA, Gessler P, McDougall J, et al. The efficacy of non-pharmacological interventions in the management of procedural pain in preterm and term neonates. A systematic literature review. Eur J Pain. 2007:11:139-52.

9. Pillai Riddell RR, Racine NM, Turcotte K, Uman LS, Horton RE, Din Osmun L, et al. Non-pharmacological management of infant and young child procedural pain. Cochrane Database Syst Rev. 2011;10:CD006275.

10. Joyce BA, Keck JF, Gerkensmeyer J. Evaluation of pain management interventions for neonatal circumcision pain. J Pediatr Health Care. 2001;15:105-14.

11. Johnston CC, Filion F, Nuyt AM. Recorded maternal voice for preterm neonates undergoing heel lance. Adv Neonatal Care. 2007;7:258-66.

12. Bo LK, Callaghan P. Soothing pain-elicited distress in Chinese neonates. Pediatrics. 2000;105:E49.

13. Lai HL, Chen CJ, Peng TC, Chang FM, Hsieh ML, Huang HY, et al. Randomized controlled trial of music during kangaroo care on maternal state anxiety and preterm infants' responses. Int J Nurs Stud. 2006:43: 139-46.

14. Johnston CC, Filion F, Campbell-Yeo M, Goulet C, Bell L, McNaughton K, et al. Enhanced kangaroo mother care for heel lance in preterm neonates: a crossover trial. J Perinatol. 2009:29:51-6.

15. Hartling L, Shaik MS, Tjosvold L, Leicht R, Liang Y, Kumar M. Music for medical indications in the neonatal period: a systematic review of randomised controlled trials. Arch Dis Child Fetal Neonatal Ed. 2009;94: F349-54.

16. Robb SL, Burns DS, Carpenter JS. Reporting guidelines for music-based interventions. Music Med. 2011;3:271-9.

17. Prasopkittikun T, Tilokskulchai F. Management of pain from heel stick in neonates: An analysis of research conducted in Thailand. J Perinat Neonatal Nurs. 2003;17:304-12.

18. Grabska J, Walden P, Lerer T, Kelly C, Hussain N, Donovan T, et al. Can oral sucrose reduce the pain and distress associated with screening for retinopathy of prematurity? J Perinatol. 2005;25:33-5.

19. Dedovic K, Duchesne A, Andrews J, Engert V, Pruessner JC. The brain and the stress axis: the neural correlates of cortisol regulation in response to stress. Neuroimage. 2009;47:864-71.

20. Cignacco E, Denhaerynck K, Nelle M, Bührer C, Engberg S. Variability in pain response to a non-pharmacological intervention across repeated routine pain exposure in preterm infants: a feasibility study. Acta Paediatr. 2009;98: 842-6.

21. Cong X, Ludington-Hoe SM, Walsh S. Randomized crossover trial of kangaroo care to reduce biobehavioral pain responses in preterm infants: a pilot study. Biol Res Nurs. 2011;13:204-16.

22. Kleberg A, Warren I, Norman E, Mörelius E, Berg AC, Mat-Ali E, et al. Lower stress responses after Newborn Individualized Developmental Care and Assessment Program care during eye screening examinations for retinopathy of prematurity: a randomized study. Pediatrics. 2008;121: e1267-78

23. Matejec R, Ruwoldt R, Bödeker RH, Hempelmann G, Teschemacher $\mathrm{H}$. Release of beta-endorphin immunoreactive material under perioperative conditions into blood or cerebrospinal fluid: significance for postoperative pain? Anesth Analg. 2003;96:481-6.
24. Anand KJ, Sippell WG, Aynsley-Green A. Randomised trial of fentanyl anaesthesia in preterm babies undergoing surgery: effects on the stress response. Lancet. 1987;1:62-6.

25. Fisk NM, Gitau R, Teixeira JM, Giannakoulopoulos X, Cameron AD, Glover VA Effect of direct fetal opioid analgesia on fetal hormonal and hemodynamic stress response to intrauterine needling. Anesthesiology. 2001;95:828-35.

26. Carbajal R, Rousset A, Danan C, Coquery S, Nolent P, Ducrocq S, et al. Epidemiology and treatment of painful procedures in neonates in intensive care units. JAMA. 2008;300:60-70.

27. Anand KJ. Consensus statement for the prevention and management of pain in the newborn. Arch Pediatr Adolesc Med. 2001:155:173-80.

28. Lehr VT, Taddio A. Topical anesthesia in neonates: clinical practices and practical considerations. Semin Perinatol. 2007;31:323-9.

29. Standley JM. A meta-analysis of the efficacy of music therapy for premature infants. J Pediatr Nurs. 2002;17:107-13.

30. Modrcin-Talbott MA, Harrison LL, Groer MW, Younger MS. The biobehavioral effects of gentle human touch on preterm infants. Nurs Sci Q. 2003;16:60-7.

31. Stevens B, Johnston C, Petryshen P, Taddio A. Premature Infant Pain Profile: development and initial validation. Clin J Pain. 1996;12:13-22.

32. Stevens B, Gibbins S. Clinical utility and clinical significance in the assessment and management of pain in vulnerable infants. Clin Perinatol. 2002;29:459-68.

33. Richardson DK, Corcoran JD, Escobar GJ, Lee SK. SNAP-II and SNAPPE-II: Simplified newborn illness severity and mortality risk scores. J Pediatr. 2001; 138:92-100

34. Craig KD, Whitfield MF, Grunau RV, Linton J, Hadjistavropoulos HD. Pain in the preterm neonate: behavioural and physiological indices. Pain. 1993;52: 287-99.

35. Johnston CC, Stevens B, Yang F, Horton L. Developmental changes in response to heelstick in preterm infants: a prospective cohort study. Dev Med Child Neurol. 1996;38:438-45.

36. Johnston CC, Stevens BJ, Yang F, Horton L. Differential response to pain by very premature neonates. Pain. 1995;61:471-9.

37. Stevens BJ, Johnston CC. Physiological responses of premature infants to a painful stimulus. Nurs Res. 1994:43:226-31.

38. Herrington CJ, Olomu IN, Geller SM. Salivary cortisol as indicators of pain in preterm infants: a pilot study. Clin Nurs Res. 2004;13:53-68.

39. Acolet D, Modi N, Giannakoulopoulos X, Bond C, Weg W, Clow A, et al. Changes in plasma cortisol and catecholamine concentrations in response to massagein preterm infants. Arch Dis Child. 1993;68:29-31.

40. Mörelius E, Theodorsson E, Nelson N. Salivary cortisol and mood and pain profiles during skin-to-skin care for an unselected group of mothers and infants in neonatal intensive care. Pediatrics. 2005;116:1105-13.

41. White-Traut RC, Schwertz D, McFarlin B, Kogan J. Salivary cortisol and behavioral state responses of healthy newborn infants to tactile-only and multisensory interventions. J Obstet Gynecol Neonatal Nurs. 2009:38:22-34.

\section{Submit your next manuscript to BioMed Central and we will help you at every step:}

- We accept pre-submission inquiries

- Our selector tool helps you to find the most relevant journal

- We provide round the clock customer support

- Convenient online submission

- Thorough peer review

- Inclusion in PubMed and all major indexing services

- Maximum visibility for your research

Submit your manuscript at www.biomedcentral.com/submit 